\title{
Detection of Wild Type and Variant mRNA Transcript of Progesterone Receptor in Human Spermatozoa of Infertile Males
}

\author{
Suresh Kumar ${ }^{1}$, Pankaj Sharma ${ }^{2}$, S.Jayaraman ${ }^{3}$ \\ ${ }^{1}$ School of Biotechnology, GGS Indraprastha University, 16C, Dwarka, Delhi \\ ${ }^{2}$ National Institute of Biologicals (Ministry of Health \& Family Welfare) Government of India, A-32, \\ Sector-62, NOIDA \\ ${ }^{3}$ Institute of Pathology (ICMR), Safdarjung Hospital, New Delhi \\ sk222ind@yahoo.com,sureshkumar@ipu.ac.in
}

\begin{abstract}
Progesterone has been seen as the main steroidal hormone mediating capacitation and acrosome reaction, the two basic processes which a sperm must undergo, in order to be successful in carrying out fertilization of ovum. Thus presence of progesterone receptors $(P R)$ on the surface of spermatozoa and their role in fertilization is under intense investigation. This study analyzed around 25 semen samples using PCR (polymerase chain reaction) technique, shows that the $m R N A$ (messenger ribonucleic acid) transcript for progesterone receptor is rarely present in fertile males. This has been confirmed by our repeated inability to detect the transcripts in case of fertile male samples. Although in some cases of infertility, bands corresponding to progesterone receptor transcripts were detected. This detection may be because of increased level of $m R N A$ expression due to the abnormal pathological condition. However, we have also detected mRNA transcript of different sizes, which further raises a possibility of alternative splicing of progesterone receptor. These splice variants again raises a possibility of involvement of this phenomenon as a cause of infertility. Although further analysis need to be done.
\end{abstract}

Keywords: Progesterone receptor; Infertility; Human spermatozoa; mRNA transcript

\section{INTRODUCTION}

Progesterone is classically considered to be a female hormone, which functions in the maintenance of pregnancy and menstrual cycle [1]. Progesterone, a member of family of steroid hormones, functions through specific nuclear receptors known as progesterone receptor (PR), which on binding to the hormone diffuses in the nucleus and act as transcription factors to regulate expression of certain genes [2]. Progesterone empowers sperm capacities, e.g. hyperactivation, acrosome response, binding to oocyte zona pellucida and entrance into oocyte. The physiological importance of these impacts has been demonstrated utilizing female genital tract liquids which balance sperm capacity as per their progesterone content. Progesterone cooperates with particular sperm binding destinations that, not at all like the classic nuclear receptor, are situated on the plasma layer of the spermatozoon. Binding studies have uncovered the vicinity of two classes of progesterone receptors in the human spermatozoon [3]. Progesterone acts through two receptors PRA and PRB, which are shown to have different transcriptional activities. Previous finding demonstrated the presence of progesterone receptor on the surface of nearly $10 \%$ of human sperms $[4,5]$. Few reports showed that sperm responsiveness to progesterone is impaired in sub fertile patients [6]. Thus strictly correlate to the ability of fertilization is related to steroid hormone (PR) receptor, which interacts with progesterone [7]. Progesterone receptor as opposed to other tissues is a membrane receptor in sperms and mediates its effects through non-genomic tyrosine phosphorylation pathways [8]. Progesterone mediating its effect through PR has been shown to be important for the capacitation, hyperactivation, binding to oocyte zona pellucida and acrosome reaction and thus the presence of PR on sperms is important for their viability. Thus analysis of receptors for steroid hormones on the surface of sperms under intense investigation for finding the reasons for the male infertility.

\section{MATERIALS AND MethodS}

\subsection{Collection of Samples}

Sperm samples from infertile patients were collected from the family welfare clinic in National Institute of Health and Family Welfare, New Delhi, India and the male infertility clinic conducted at 
Safdarjung Hospital, New Delhi, India. The samples were collected as ethical guideline and the informed consent was taken from each subject before collection of samples.

\subsection{RNA Isolation and RT-PCR}

A total of 25 spermatozoa samples in which 10 are normal and 15 are infertile sample were used to isolate RNA using TRIzol RNA isolation kit (Invitrogen Corporation, USA). Chloroform and isopropranol (Sigma). All PCR reagents and enzymes (Promega). Primers specific to conventional Progesterone receptor (PR1 5' GATTCAGAAGCCAGCCAGAG3') and reverse primer (PR2 5'TGCCTCTCGCCTAGTTGATT 3') of product size of around $533 \mathrm{bp}$. For PCR reaction $5 \mu \mathrm{l}$ of cDNA synthesized by RT reaction added $0.5 \mu \mathrm{l}$ of $10 \mathrm{X}$ dNTP, $0.1 \mu \mathrm{l}$ each of forward and reverse primers $(100 \mu \mathrm{mol})$, Taq buffer (10X) $2.5 \mu \mathrm{l}$, Taq polymerase ( 1 unit) $0.125 \mu$ l. Made final volume to $25 \mu \mathrm{l}$ by adding autoclaved water. The program comprised of 40 cycles of denaturation at $94^{\circ} \mathrm{C}$ for $1 \mathrm{~min}$, annealing at $60^{\circ} \mathrm{C}$ for $1 \mathrm{~min}$ and extension at $72^{\circ} \mathrm{C}$ for $1 \mathrm{~min}$. The negative control did not include cDNA in the reaction mixture. The product was analyzed on a $1.2 \%$ agarose gel stained with ethidium bromide and visualized under UV transillumination.

\subsection{Immunocytochemistry}

Roughly $1 \times 10^{6}$ spermatozoa in $20 \mu$ of PBS were spread on clean, oil free slides, air-dried, and settled in chilled methanol for $30 \mathrm{~min}$. The slides were washed twice with $1 \times$ PBS and once with PBS-T (0.5\% Tween 20 in $1 \times$ PBS) for $10 \mathrm{~min}$ at room temperature. Subsequent to washing, the sperm layer was permeabilized with $0.1 \%$ sodium deoxycholate in $1 \times \mathrm{PBS}$ at $4^{\circ} \mathrm{C}$ for $30 \mathrm{~min}$. Smears were washed with PBS-T for $5 \mathrm{~min}$, and obstructed in 1\% BSA in $1 \times$ PBS at room temperature for 20-25 min. Slides were hatched with antisera against the carboxyl end of PR weakened 1:100 in 1× PBS at $4^{\circ} \mathrm{C}$ for $18-20 \mathrm{~h}$. The slides were washed with PBS-T for $5 \mathrm{~min}$ and afterward incubated with biotin-conjugated secondary antibody diluted 1:400 in $1 \times$ PBS for $1 \mathrm{~h}$ at room temperature. The slides were washed twice with $1 \times$ PBS and incubated with avidin-biotin complex for $30 \mathrm{~min}$ at room temperature. The slides were then washed twice with $1 \times$ PBS at room temperature for $30 \mathrm{~min}$ each, trailed by treatment with $0.04 \%$ diaminobenzidine in $1 \times \mathrm{PBS}$ with $0.05 \% \mathrm{H}_{2} \mathrm{O}_{2}$ for $10 \mathrm{~min}$. The slides were counterstained with $1 \%$ hematoxylin for $2 \mathrm{~min}$, got dried out for $10 \mathrm{~min}$ each, and kept in xylene for $2 \mathrm{~h}$ took after by mounting in DPX. Specificity of staining was assessed a negative control (1\% BSA without immune response). The slides were analyzed utilizing the $100 \times$ target of a brightfield microscope (Leica). Counterstained spermatozoa demonstrating brown colour shading at the head region were considered PR-positive. Spermatozoa that did not react with the antibodies against PR had no brown colour hastens and seemed blue all throughout because of counterstaining and were considered PR-negative.

\section{RESULTS AND DISCUSSION}

When primers correspond to the DNA binding and hormone binding domains of the conventional PR were used in RT-PCR to detect the PR transcript in human spermatozoa. Two type products were visualized. One corresponding to nearly 250 bp (Fig. 1 Lane 3,6) while other nearly 500 bp (Fig 1. Lane 4,5). These bands of two sizes show the splice variants of Progesterone receptor mRNA transcript. In case of four infertile males, bands corresponding to Progesterone receptor transcript were obtained.

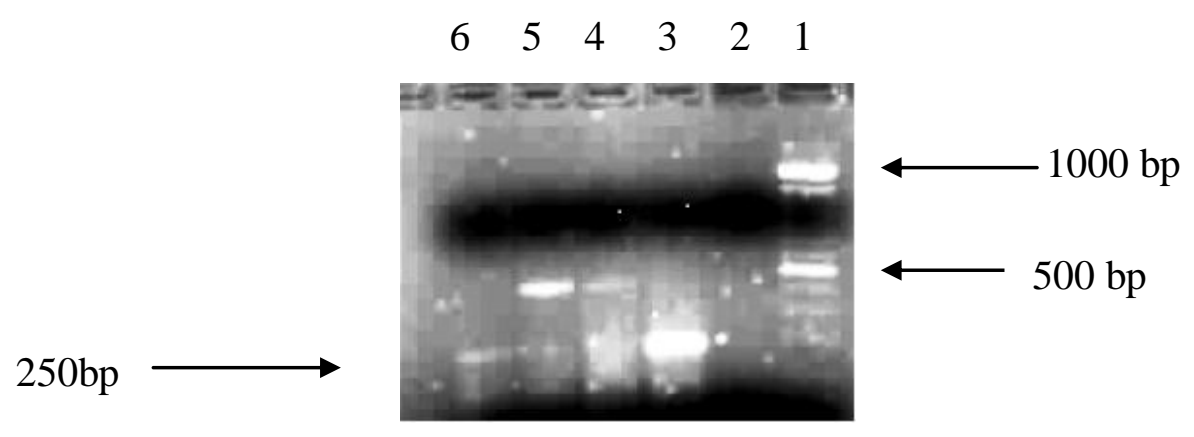

Figure1. RT-PCR Detection of mRNA PR Transcripts in Infertile Male Samples

Lane-1 shows the 1000 bp marker, while lanes 3-6 shows the bands corresponding to PR. Lanes 4 and 5 shows a band corresponding to nearly 500 bp while 3 and 6 shows a band of size nearly $250 \mathrm{bp}$. Lane-2 is negative control. 


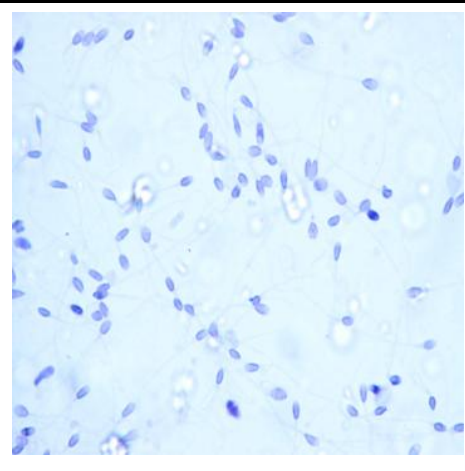

A

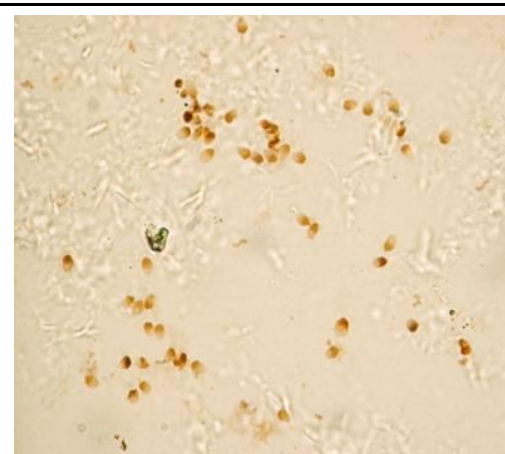

B

Figure2. Detection of $P R$ using antibodies against conventional PR in spermatozoa from men with (a) Negative control (no antibody), (b) Brown colour indicates positive staining for PR. Blue color appears because of counterstaining with hematoxylin. Spermatozoa were visualizes with a 100X objective

Progesterone receptor in human sperms has been shown to be involved in acrosome reaction, capacitation, hyper activation and binding to oocyte zona-pellucida and all the processes are important for fertilization of oocyte with sperms. The expression of progesterone receptors has been shown by immunohistochemistry in case of fertile males than infertile males [9] and also the presence of PR transcript in human spermatozoa [10] but no comparative study for presence at mRNA transcript between fertile and infertile has been performed. Our group for the first time is attempting to characterize the expression of PR in fertile and infertile human spermatozoa.

Total RNA was isolated from sperms samples, and its integrity was checked on formaldehyde gel. The RNA visualized on gel might correspond to mitochondrial ribosomal RNA, as the nucleus of sperm being a highly compact structure is not believed to be involved in the process of translation and so the presence of ribosomes or rRNA in nuclear part is not expected. mRNA (if present) in the nuclear part is thought to be preformed stored transcript not generated due to transcription, which in any case will be of very low number. The formation of cDNA was confirmed by detection of transcripts for house keeping genes GAPDH and B-actin. Although their presence cannot be correlated to the presence of mRNA in the nuclear region, as one of these genes code for a protein involved in energy generation pathways and other is a structural protein. So their transcripts may be localized to the mid-piece region containing mitochondria. The RT-PCR product was also not a result of DNA contamination as we did not obtained any products when the RT step was removed. mRNA transcript for the progesterone receptor was not detected by standard PCR method in case of fertile male samples. Immunohistochemically, it has been shown that PR is more numerous on the surface of sperms from fertile males than infertile males [11]. In view of this, it was speculated that mRNA would be detected in fertile males and not in the infertile ones. Although in our present study transcripts were not-detected by RT-PCR in fertile males. This may be because the number of transcripts present (in total) in the samples were quite low. This may be because PR are present only on $10 \%$ of sperms and transcription from nuclear genome is not expected. Mitochondrial genome being similar to microbial genome is not expected to make PR transcripts. The transcripts for receptor for steroid hormones have been detected in early stages of formation of spermatozoa although their expression decreases with maturation. A mature sperm with preformed receptor doesn't seem to have need for these transcripts [12]. Then it is only the pre-stored transcripts in the nucleus, which are thought to contain PR transcripts, but their presence level in the samples is not thought to be of detectable level. Although, in case of four infertile patients transcripts for PR were detected. This may be because as they are diseased samples so they might be ejaculating premature spermatozoa. One study has reported the presence of progesterone receptor transcripts in human spermatozoa but in their method they have pooled the samples from various individuals and so their result doesn't establish whether the PR transcripts were present in all the samples or from a same individual, which might be diseased (infertile) as we have detected. Moreover they haven't disclosed the fertility status of those patients [13]. In another study, the genomic transcripts have been detected by RT-PCR. They also conclude that as in many previous studies PR transcripts were not detected, so it may be some post transcriptional modification which is playing the role in detection $[14,15,16]$. Moreover in our results we are getting bands of two sizes $250 \mathrm{bp}$ (variant) and $500 \mathrm{bp}$ (wild type) for the PR transcript. 
These bands may have aroused due to splice variations, which might lead to abnormal pathological conditions such as infertility. We are speculating so because splice variants are already reported in abnormal conditions such as breast cancer [17] although further analysis is required. We are the first group, which are trying to correlate the male infertility with splice variants in Progesterone receptor transcripts. Thus all these results show that the detection of transcripts might be correlated to some sort of pathological condition although a better standardization of the PCR cannot be declined. A correlation of detection of variants with male fertility and infertility can be a good diagnostics marker and can help further in elucidation of the reasons for various pathological conditions associated with fertility status of man.

\section{Conclusion}

In conclusion, both wild type and variant mRNA PR transcript were obtained from the infertile human samples by RT-PCR technique, further studies are required in future to correlates with male fertility and infertile condition which may be used a suitable diagnostic marker in future.

\section{ACKNOWLEDGEMENT}

I acknowledge the cooperation of the patients who consented to give the sample which made this study possible.

\section{REFERENCES}

[1] Henson M. C., Pregnancy maintenance and the regulation of placental progesterone biosynthesis in baboon, Hum. Reprod. Upd. 4(4), 389-405 (1998).

[2] Revelli A., Massobrio M. and Tesarik J., Non genomic action of Steroid hormones in Reproductive Tissues, End. Rev. 19(1), 3-17 (1998).

[3] Lösel R., Breiter S., Seyfert M., Wehling M. and Falkenstein E., Classic and nonclassic progesterone receptors are both expressed in human spermatozoa, Horm. Metab. Res. 37(1), 10-14 (2005).

[4] Luconi M., Bonaccorsi L., Maggi M., Pecchioli P., Krausz C., Forti G. and Baldi E., Identification and characterization of functional non-genomic progesterone receptors on human sperm membrane, J. Clin. Endo. Meta. 83(3), 877-885 (1998).

[5] Tesarik J., Mendoza C., Moos J. and Carreras A., Selective expression of a Progesterone receptor on the human surface, Fertil. Steril. 58(4), 784-792 (1992).

[6] Tesarik J. and Medoza C., Defective function of a non-genomic progesterone receptor as a sole sperm anomaly in infertile patients, Fertil. Steril. 58, 793-797 (1992).

[7] Blackmore P. F. and Latanzio F., Cell surface localization of a noval progesterone receptor on the head of human sperms, Bio. Res. Comm. 181, 331-336 (1991).

[8] Tesarik J., Moos J. and Carmen M., Stimulation of Protein tyrosin phosphorylation by a Progesterone Receptor on the cell surface of human sperms, Endocrinol. 133(1), 328-335 (1993).

[9] Contreras H. R. and Llanos M. N., Detection of progesterone receptors in human spermatozoa and their correlation with morphological and functional properties, Int. J. Androl. 24(4), 246-252 (2001).

[10] Sachdeva G., Shah C. A., Kholkute S. D. and Puri C. P., Detection of progesterone receptor transcript in human spermatozoa, Biol. Reprod. 62(6),1610-1614 (2000).

[11] Kotwicka M. and Warchoł J. B., Expression of progesterone membrane receptor in spermatozoa from normozoospermic and oligozoospermic men, Folia. Histochem. Cytobiol. 39(2), 139-140 (2001).

[12] Gadkar S., Shah C. A., Sachdeva G., Samant U. and Puri C. P., Progesterone receptor as an indicator of sperm function, Biol. Reprod. 67(4), 1327-1336 (2001).

[13] Boomsma D. and Paoletti J., A review of current research on the effects of Progesterone, Int. J. Pharma. Comp. 6(4), 245-249 (2002).

[14] Jacob A., Hurley I., Mandel F. S., Hershlag A., Cooper G. W. and Benoff S., Human Sperm non nuclear progesterone receptor expression is a noval marker for the fertilization outcome, Mol. Hum. Reprod. 4(6), 533-542 (1998). 
Detection of Wild Type and Variant mRNA Transcript of Progesterone Receptor in Human Spermatozoa of Infertile Males

[15] Lishko P. V., Botchkina I. L. and Kirichok Y., Progesterone activates the principal Ca2+ channel of human sperm, Nature. 471(7338), 387-391 (2011).

[16] Cheng J. J., Gu C. H., Liang W. J. and Zheng L. W., Progesterone and its receptor in male reproduction, Zhonghua. Nan. Ke. Xue. 18(9), 840-842 (2012).

[17] Leygue E., Dotzlaw H., Watson P. H. and Murphy L. C., Identification of novel exondeleted progesterone receptor variant mRNAs in human breast tissue, Biochem. Biophys. Res. Comm. 228(1), 63-68 (1996). 